American Journal of Applied Sciences 6 (2): 273-275, 2009

ISSN 1546-9239

(C) 2009 Science Publications

\title{
A Fixed Point Theorems in L-Fuzzy Quasi-Metric Spaces
}

\author{
${ }^{1,2}$ Reza Saadati and ${ }^{1}$ S. Mansour Vaezpour \\ ${ }^{1}$ Department of Mathematics and Computer Sciences, \\ Amirkabir University of Technology, Tehran, Iran \\ ${ }^{2}$ Islamic Azad University-Ayatollah Amoly Branch, Amol, Iran
}

\begin{abstract}
At first we considered the L-fuzzy metric space notation which is useful in modeling some phenomena where it is necessary to study the relationship between two probability functions as well observed in Gregori et al. [A note on intuitionistic fuzzy metric spaces. Chaos, Solitons and Fractals 2006; 28: 902-905]. Then we introduced the concept of fixed point theorem in L-fuzzy metric space and finally, showed that every contractive mapping on an L-fuzzy metric space has a unique fixed point.
\end{abstract}

Key words: Fixed-point theorem, fuzzy sets

\section{INTRODUCTION}

The concept of fuzzy sets was introduced initially by Zadeh ${ }^{[1]}$ in 1965 . Various concepts of fuzzy metric spaces were considered in George and Veeramani ${ }^{[2]}$ and Mihet $^{[3,4]}$.

In this research, at first we shall adopt the usual terminology, notation and conventions of L-fuzzy metric spaces introduced by Saadati et al ${ }^{[5]}$ which are a generalization of fuzzy metric spaces $^{[2]}$ and intuitionistic fuzzy metric spaces ${ }^{[6,7]}$. Then we consider the fixed point theorem on such spaces and show that every contractive mapping on non-Archimedean Lfuzzy metric space has a unique fixed point.

Definitions 1.1: Goguen ${ }^{[8]}$ let $\mathrm{L}=\left(\mathrm{L}, \mathrm{S}_{\mathrm{L}}\right)$ be a complete lattice and $\mathrm{U}$ a non-empty set called universe. An Lfuzzy set $A$ on $U$ is defined as a mapping. A: $U \rightarrow L$. For each $\mathrm{u}$ in $\mathrm{U}, \mathrm{A}(\mathrm{u})$ represents the degree (in $\mathrm{L}$ ) to which u satisfies A.

Classically, a triangular norm $\mathrm{T}$ on $([0,1], \leq)$ is defined as an increasing, commutative, associative mapping $\mathrm{T}:[0,1]^{2} \rightarrow[0,1]$ satisfying $(1, \mathrm{x})=\mathrm{x}$ for all $\mathrm{x}$ $\in[0,1]$. These definitions can be straightforwardly extended to any lattice $\mathrm{L}=\left(\mathrm{L}, \mathrm{S}_{\mathrm{L}}\right)$.

Definitions 1.2: A triangular norm (t-norm) on $\mathrm{L}$ is a mapping $\tau: \mathrm{L}^{2} \rightarrow \mathrm{L}$ satisfying the following conditions:

- $(\forall \mathrm{x} \in \mathrm{L})\left(\tau\left(\mathrm{x}, 1_{\mathrm{L}}\right)=\mathrm{x}\right)$ (boundary condition)
- $\quad\left(\forall(\mathrm{x}, \mathrm{y}) \in \mathrm{L}^{2}\right)(\tau(\mathrm{x}, \mathrm{y})=\tau(\mathrm{y}, \mathrm{x}))$ (commutativity)

- $\quad\left(\forall(\mathrm{x}, \mathrm{y}, \mathrm{z}) \in \mathrm{L}^{3}\right)(\tau(\mathrm{x}, \tau(\mathrm{y}, \mathrm{z}))=\tau(\tau(\mathrm{x}, \mathrm{y}), \mathrm{z}))$

(associativity)

$\left(\forall\left(\mathrm{x}, \mathrm{x}^{\prime}, \mathrm{y}, \mathrm{y}^{\prime}\right) \in \mathrm{L}^{4}\right)$

$\left(\mathrm{x} \leq_{\mathrm{L}} \mathrm{x}^{\prime}\right.$ and $\left.\mathrm{y} \leq_{\mathrm{L}} \mathrm{y}^{\prime} \Rightarrow \tau(\mathrm{x}, \mathrm{y}) \leq_{\mathrm{L}} \tau\left(\mathrm{x}^{\prime}, \mathrm{y}^{\prime}\right)\right)$

(monotonicity)

The t-norm $\tau$ is Hadzic type if $\tau(x, y) \geq_{L} \wedge(x, y)$ for every $\mathrm{x}, \mathrm{y} \in \mathrm{L}$ where

$$
\wedge(x, y)=\left\{\begin{array}{l}
x, \text { if } x \leq_{L} y \\
y, \text { if } y \leq_{L} x
\end{array}\right.
$$

Triangle norms are recursively defined by $\tau^{1}=\tau$ and

$$
\tau^{\mathrm{n}}\left(\mathrm{x}_{(1)}, \ldots, \mathrm{x}_{(\mathrm{n}+1)}\right)=\tau\left(\tau^{\mathrm{n}-1}\left(\mathrm{x}_{(1)}, \ldots, \mathrm{x}_{(\mathrm{n})}\right), \mathrm{x}_{(\mathrm{n}+1)}\right)
$$

for $\mathrm{n} \geq 2, \mathrm{x}_{(\mathrm{i})} \in \mathrm{L}$ and $\mathrm{i} \in\{1,2, \ldots, \mathrm{n}+1\}$.

Definition 1.3: Deschrijver et al. ${ }^{[9]} \mathrm{A}$ negator on $\mathrm{L}$ is any decreasing mapping $\mathrm{N}$ : $\mathrm{L} \rightarrow \mathrm{L}$ satisfying $\mathrm{N}\left(0_{\mathrm{L}}\right)=1_{\mathrm{L}}$ and $\mathrm{N}\left(1_{\mathrm{L}}\right)=0_{\mathrm{L}}$. If $\mathrm{N}(\mathrm{N}(\mathrm{x}))=\mathrm{x}$ for all $\mathrm{x} \in \mathrm{L}$, then $\mathrm{N}$ is called an involutive negator.

In this research the negator $\mathrm{N}: \mathrm{L} \rightarrow \mathrm{L}$ is fixed. The negator $\mathrm{N}_{\mathrm{s}}$ on $([0,1], \leq)$ defined as $\mathrm{N}_{\mathrm{s}}(\mathrm{x})=1$ - $\mathrm{x}$, for all $\mathrm{x}$ $\in[0,1]$, is called the standard negator on $([0,1], \leq)$.

Corresponding Author: Reza Saadati, Department of Mathematics and Computer Sciences, Amirkabir University of Technology, Tehran, Iran 
Definition 1.4: The triple $(X, M, \tau)$ is said to be an Lfuzzy quasi-metric space if $\mathrm{X}$ is an arbitrary (nonempty) set, $\tau$ is a continuous t-norm on $\mathrm{L}$ and $M$ is an L-fuzzy set on $\left.\mathrm{X}^{2} \times\right] 0,+\infty[$ satisfying the following conditions for every $\mathrm{x}, \mathrm{y}, \mathrm{z}$ in $\mathrm{X}$ and $\mathrm{t}, \mathrm{s}$ in $] 0,+\infty[$ :

- $\mathrm{M}(\mathrm{x}, \mathrm{y}, \mathrm{t})>_{\mathrm{L}} 0_{\mathrm{L}}$

- $M(x, y, t)=M(y, x, t)=1_{L}$ forall $t>0$ if and only if $\mathrm{x}=\mathrm{y}$

- $\quad \tau(\mathrm{M}(\mathrm{x}, \mathrm{y}, \mathrm{t}), \mathrm{M}(\mathrm{y}, \mathrm{z}, \mathrm{s})) \leq_{\mathrm{L}} \mathrm{M}(\mathrm{x}, \mathrm{z}, \mathrm{t}+\mathrm{s})$

- $\mathrm{M}(\mathrm{x}, \mathrm{y},):.] 0, \infty[\rightarrow \mathrm{L}$ is continuous

- $\lim _{\mathrm{t} \rightarrow \infty} \mathrm{M}(\mathrm{x}, \mathrm{y}, \mathrm{t})=1_{\mathrm{L}}$.

In this case, $\mathrm{M}$ is called an L-fuzzy quasi-metric.

If, in the above definition, the triangular inequality (c) is replaced by

$$
\begin{aligned}
& \text { (NA) } \tau(M(x, y, t), M(y, z, s)) \\
& \leq_{L} M(x, z, \max \{t, s\}) \forall x, y, z \in X, \quad \forall t, s>0
\end{aligned}
$$

or, equivalently,

$$
\begin{aligned}
& \tau(\mathrm{M}(\mathrm{x}, \mathrm{y}, \mathrm{t}), \mathrm{M}(\mathrm{y}, \mathrm{z}, \mathrm{t})) \leq_{\mathrm{L}} \\
& \mathrm{M}(\mathrm{x}, \mathrm{z}, \mathrm{t}) \quad \forall \mathrm{x}, \mathrm{y}, \mathrm{z} \in \mathrm{X}, \mathrm{t}>0 .
\end{aligned}
$$

Then the triple $(\mathrm{X}, \mathrm{M}, \tau)$ is called a nonArchimedean L-fuzzy quasi-metric space ${ }^{[3,4]}$.

For $\mathrm{t} \in] 0,+\infty[$, we define the closed ball $\mathrm{B}[\mathrm{x}, \mathrm{r}, \mathrm{t}]$ with center $\mathrm{x} \in \mathrm{X}$ and radius $\mathrm{r} \in \mathrm{L} \backslash\left\{0_{\mathrm{L}}, 1_{\mathrm{L}}\right\}$, as

$$
B[x, r, t]=\left\{y \in X: M(x, y, t) \geq_{L} N(r)\right\}
$$

Definition 1.5: A sequence $\left\{x_{n}\right\}_{n \in N}$ in an L-fuzzy quasi-metric space $(\mathrm{X}, \mathrm{M}, \tau)$ is called a right (left)

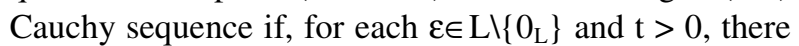
exists $n_{0} \in N$ Such that, for all $m \geq n \geq n_{0}\left(n \geq m \geq n_{0}\right)$,

$$
\mathrm{M}\left(\mathrm{x}_{\mathrm{m}}, \mathrm{x}_{\mathrm{n}}, \mathrm{t}\right)>_{\mathrm{L}} \mathrm{N}(\varepsilon)
$$

The sequence $\left\{x_{n}\right\}_{n \in N}$ is said to be convergent to $\mathrm{x} \in \mathrm{X}$ in the L-fuzzy quasi-metric space $(\mathrm{X}, \mathrm{M}, \tau)$ (denoted by $\mathrm{x}_{\mathrm{n}} \stackrel{\mathrm{M}}{\longrightarrow} \mathrm{x}$ ) if $\mathrm{M}\left(\mathrm{x}_{\mathrm{n}}, \mathrm{x}, \mathrm{t}\right)=\mathrm{M}\left(\mathrm{x}, \mathrm{x}_{\mathrm{n}}, \mathrm{t}\right) \rightarrow 1_{L}$, whenever $n \rightarrow+\infty$ for every $t>0$. An L-fuzzy quasimetric space is said to be right (left) complete if and only if every right (left) Cauchy sequence is convergent.
Definition 1.6: Let $(X, M, \tau)$, be an L-fuzzy metric space and let $\mathrm{N}$, be a negator on L. Let $A$ be a subset of $\mathrm{X}$, then the LF-diameter of the set $\mathrm{A}$ is the function defined as:

$$
\delta_{A}(s)=\sup _{t<s} \inf _{x, y \in A} M(x, y, t)
$$

A sequence $\left\{A_{n}\right\}_{n \in N}$ of subsets of an L-fuzzy quasi-metric space is called decreasing sequence if $\mathrm{A}_{1} \supseteq \mathrm{A}_{2} \supseteq \mathrm{A}_{3} \supseteq \ldots$

The following lemma gives conditions under which the intersection of such sequences is nonempty.

Lemma 1.7: Let $(X, M, \tau)$ be a left complete L-fuzzy metric space and let $\left\{A_{n}\right\}_{n \in N}$, be a decreasing sequence of nonempty closed subsets of $X$ such that $\delta_{A n}(t) \rightarrow 1_{L}$ as $n \rightarrow \infty$. Then $A=\bigcap_{n=1}^{\infty} A_{n}$ contains exactly one point.

Proof: From the assumption $\delta_{\mathrm{An}}(\mathrm{t}) \rightarrow 1_{\mathrm{L}}$, it is evident that the set A can't contain more than one element. So it is enough to show that $\mathrm{A}$ is nonempty. Let $x_{n}$ be a point in $A_{n}$. Since $\delta_{A n}(t) \rightarrow 1_{L}$, by definition of $5 F-$ diameter, $\left\{x_{n}\right\}_{n \in N}$, is a left Cauchy sequence in $X$. Since $(\mathrm{X}, \mathrm{M}, \tau)$, is left complete, $\left\{\mathrm{x}_{\mathrm{n}}\right\}_{\mathrm{n} \in \mathrm{N}}$, has a limit $\mathrm{x}$. We show that $\mathrm{x}$ is in $\mathrm{A}$ and for this it suffices to show that $\mathrm{X}$ is in $A_{n_{0}}$, for a fixed but arbitrary $n_{0}$. If $\left\{x_{n}\right\}_{n \in N}$, has only finitely many distinct points, then $\mathrm{Ax}$ is that point infinitely repeated and is therefore in $A_{n_{0}}$. If $\left\{x_{n}\right\}_{n \in N}$ has infinitely many distinct points, then $\mathrm{x}$ is a limit point of the set of points of the sequence, so it is a limit point of the subset $\left\{\mathrm{x}_{\mathrm{n}}: \mathrm{n} \geq \mathrm{n}_{0}\right\}$ of the set of the points of the sequence which implies it is a limit point of $A_{n_{0}}$ and since $A_{n_{0}}$ is closed, it is in $A_{n_{0}}$.

Corollary 1.8: Let $(X, M, \tau)$ be a left complete Lfuzzy metric space and let $\left\{\mathrm{A}_{\mathrm{i}}\right\}_{\mathrm{i} \in \mathrm{I}}$ be a family of closed subsets of $\mathrm{X}$, which has the finite intersection property and for each $\varepsilon>0$, contains a set of LF-diameter less than $\varepsilon$, then $\bigcap_{i \in I} A_{i} \neq \phi$.

Proof: For each $n=1,2, \ldots$ let $i_{n} \in I$ denote an index such that

$$
\delta_{\mathrm{A}_{\mathrm{in}_{\mathrm{n}}}}(\mathrm{t})=\mathrm{M}\left(\mathrm{x}, \mathrm{y}, \frac{1}{\mathrm{n}}\right)
$$

for every $x \neq y$. The set $A_{n}=\bigcap_{j \leq n} A_{i_{j}}$ satisfy the assumption of the last lemma. Therefore $\bigcap_{n=1}^{\infty} A_{n}$, 
contains exactly one point say $\mathrm{x}_{0}$. Then $\mathrm{x}_{0} \in \mathrm{A}_{\mathrm{i}_{1}}$, for $i_{1} \in I$. Indeed define $A_{n}^{\prime}=A_{i_{1}} \cap A_{n}$ for $n=1,2, \ldots$ Now

$$
\phi \neq \bigcap_{n=1}^{\infty} A_{n}^{\prime}=A_{i_{1}} \cap\left(\bigcap_{n=1}^{\infty} A_{n}\right)=A_{i_{1}} \cap\left\{x_{0}\right\} .
$$

Definition 1.9: Let $(X, M, \tau)$ be an L-fuzzy metric space. A mapping $\Delta: \mathrm{X} \rightarrow \mathrm{X}$ is said to be contractive if whenever $\mathrm{X}$ and $\mathrm{y}$ are distinct point in $\mathrm{X}$, we have

$$
\mathrm{M}(\Lambda \mathrm{x}, \Lambda \mathrm{y}, \mathrm{t})>_{\mathrm{L}} \mathrm{M}(\mathrm{x}, \mathrm{y}, \mathrm{t})
$$

\section{MAIN RESULT}

Theorem 2.1: Let $(\mathrm{X}, \mathrm{M}, \tau)$ be non-Archimedean Lfuzzy metric space, in which $\tau$ is Hadzic type. If $\Delta$ : $\mathrm{X} \rightarrow \mathrm{X}$ is a contractive mapping then $\Delta$ has a unique fixed point.

Proof: Let $B_{x}=B[x, \eta, t]$ with $\eta(x, t)=N(m(x, \Delta x, t))$ and $t>0$. Let $A$ be the collection of all these balls for all $x \in X$. The relation $B_{x} \leq B_{y}$ if and only if $B_{y} \subseteq B_{x}$ is a partial order in A. Consider a totally ordered subfamily $\mathrm{A}_{\mathrm{i}}$ of A. From Corollary 1.8, we have,

$$
\bigcap_{\mathrm{B}_{\mathrm{x}} \in \mathrm{A}_{1}} \mathrm{~B}_{\mathrm{x}}=\mathrm{B} \neq \varphi
$$

Let $\mathrm{y} \in \mathrm{B}$ and $\mathrm{B}_{\mathrm{x}} \in \mathrm{A}_{1}$, then

$$
\mathrm{M}(\mathrm{x}, \mathrm{y}, \mathrm{t}) \geq_{\mathrm{L}} \mathrm{N}(\mathrm{N}(\mathrm{M}(\mathrm{x}, \Lambda \mathrm{x}, \mathrm{t})))=\mathrm{M}(\mathrm{x}, \Lambda \mathrm{x}, \mathrm{t})
$$

Now, if $\mathrm{x}_{0} \in \mathrm{B}_{\mathrm{y}}$, then

$$
\begin{aligned}
& M\left(x_{0}, y, t\right) \geq_{L} N(N(M(y, \Lambda y, t))) \\
& \geq_{L} \tau^{2}(M(y, x, t), M(x, \Lambda x, t), M(\Lambda x, \Lambda y, t)) \\
& \geq_{L} M(x, \Lambda x, t) .
\end{aligned}
$$

Thus

$$
M\left(x_{0}, y, t\right) \geq_{L} M(x, \Lambda x, t)
$$

Now, by using (1) and (2) we obtain

$$
\begin{aligned}
& M\left(x_{0}, x, t\right) \geq_{L} \tau\left(M\left(x_{0}, y, t\right), M(x, y, t)\right) \\
& \geq_{L} \tau(M(x, \Lambda x, t), M(\Lambda x, x, t)) \\
& \geq_{L} M(x, \Lambda x, t) .
\end{aligned}
$$

Therefore $\mathrm{x}_{0} \in \mathrm{B}_{\mathrm{x}}$ and $\mathrm{B}_{\mathrm{y}} \subseteq \mathrm{B}_{\mathrm{x}}$ implies that $\mathrm{B}_{\mathrm{x}} \leq \mathrm{B}_{\mathrm{y}}$ for all $B_{x} \in A_{1}$. Thus $B_{y}$ is an upper bound in $A$ for family $\mathrm{A}_{1}$. Hence by Zorn's Lemma, A has a maximal element, say, $\mathrm{B}_{\mathrm{z}}$, for some $\mathrm{z} \in \mathrm{X}$. We claim that $\mathrm{z}=\Delta \mathrm{z}$.

Suppose that $\mathrm{z} \neq \Delta \mathrm{z}$. Since $\Delta$ is contractive, therefore

$$
\mathrm{M}\left(\Lambda \mathrm{z}, \Lambda^{2} \mathrm{z}, \mathrm{t}\right)>_{\mathrm{L}} \mathrm{M}(\mathrm{z}, \Lambda \mathrm{z}, \mathrm{t})
$$

where $\Delta^{2}=\Delta 0 \Delta$ and

$$
\Lambda \mathrm{z} \in \mathrm{B}[\Lambda \mathrm{z}, \eta(\Lambda \mathrm{z}, \mathrm{t}), \mathrm{t}] \cap \mathrm{B}[\mathrm{z}, \eta(\mathrm{z}, \mathrm{t}), \mathrm{t}]
$$

Therefore $\mathrm{B}_{\Delta \mathrm{z}} \subseteq \mathrm{B}_{\mathrm{z}}$ and $\mathrm{z}$ is not in $\mathrm{B}_{\Delta \mathrm{z}}$. Thus $\mathrm{B}_{\Delta \mathrm{z}} \subset \mathrm{B}_{\mathrm{z}}$, which contradicts the maximality of $\mathrm{B}_{\mathrm{z}}$. Hence $\Delta$ has a fixed point.

Uniqueness easily follows from contractive condition.

\section{CONCLUSION}

In this research we introduce the concept of fixed point theorem in L-fuzzy metric spaces and present some results.

\section{REFERENCES}

1. Zadeh, L.A., 1965. Fuzzy sets. Inform. Control, 8: 338-353. doi: 10.1016/S0019-9958(65)90241-X

2. George, A. and P. Veeramani, 1994. On some result in fuzzy metric space. Fuzzy Sets Syst. 64: 395-399. doi: 10.1016/0165-0114(94)90162-7

3. Mihet, D., 2005. On the existence and the uniqueness of fixed points of Sehgal contractions. Fuzzy Sets Syst, 156: 135-141. doi: 10.1016/j.fss.2005.05.024.

4. Mihet, D., 2004. A Banach contraction theorem in fuzzy metric spaces, Fuzzy Sets and Syst. 144: 431-439. doi: 10.1016/S0165-0114(03)00305-1.

5. Saadati, R., A. Razani and H. Adibi, 2007. A common fixed point theorem in L-fuzzy metric spaces. Chaos, Solitons Fractals, 33: 358-363. doi: 10.1016/j.chaos.2006.01.023.

6. Park, J.H., 2004. Intuitionistic fuzzy metric spaces. Chaos Solitons Fractals, 22: 1039-1046. doi: 10.1016/j.chaos.2004.02.051

7. Saadati, R. and J.H. Park, 2006. On the intuitionistic fuzzy topological spaces. Chaos, Solitons Fractals, 27: 331-344. doi: 10.1016/j. chaos.2005.03.019

8. Goguen, J., 1976. L-fuzzy sets. J. Math. Anal. Applied, 18: 145-174. doi: 10.1016/0022-247X (67)90189-8.

9. Deschrijver, G. and E.E. Kerre, 2003. On the relationship between some extensions of fuzzy set theory. Fuzzy Sets Syst., 133: 227-235. doi: 10.1016/S0165-0114(02)00127-6. 